\title{
A utilização de metodologias ativas e seu impacto no ensino de Química nos cursos de Engenharia: um estudo de caso do campus da UFC em Crateús
}

\author{
The use of active methodologies and its impact on Chemistry teaching in Engineering courses: a \\ case study of the UFC campus in Crateús
}

El uso de metodologías activas y su impacto en la enseñanza de Química en cursos de Ingeniería: un estudio de caso del campus UFC en Crateús

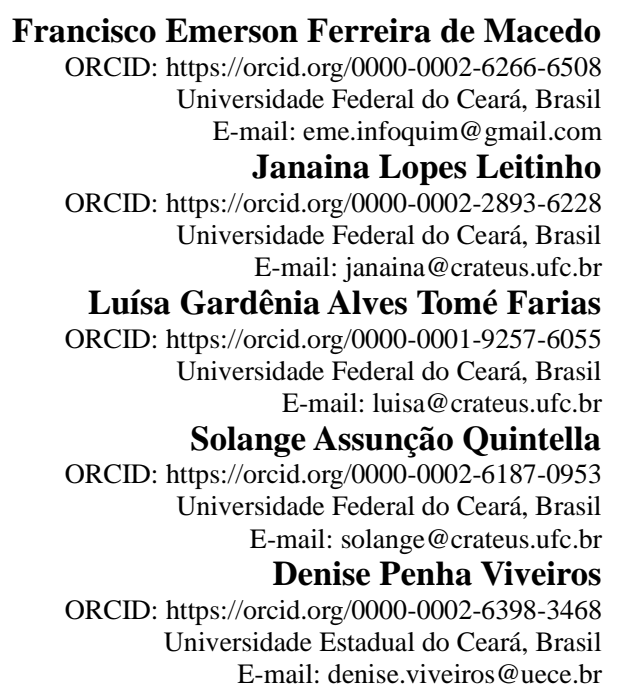

\begin{abstract}
Resumo
As metodologias ativas têm sido um meio inovador de construção de conhecimento dos alunos dentro e fora da sala de aula. Entre elas estão a Aprendizagem Baseada em Problemas, Aprendizagem Cooperativa e Sala de Aula Invertida. Tais métodos foram usados de forma associada com métodos investigativos no ensino de Química na Universidade Federal do Ceará Campus Crateús, em uma turma de repetentes. A partir disso, foi analisada a eficácia deste método em comparação à metodologia tradicional de sala de aula. Em adição às avaliações continuadas e formativas realizadas com os alunos, questionários de opinião aplicados pela professora e monitor foram utilizados para obter os dados da pesquisa. Após a aplicação do método híbrido, os alunos foram consultados e os seguintes dados foram observados: 83,3\% mostraram-se satisfeitos com seu aprendizado, 93,3\% afirmaram ter suas dúvidas sanadas e 60,0\% indicaram estar menos pressionados quanto à forma de avaliação. Há ainda que se considerar uma redução de alunos desistentes $(4,9 \%)$ da disciplina quando comparados com turmas tradicionais. Assim, pode-se inferir que os estudantes apresentam ganhos significativos na compreensão conceitual e competências abordadas pela disciplina de Química. Palavras-chave: Sala de aula invertida; Metodologia híbrida; Química geral.
\end{abstract}

\begin{abstract}
Active methodologies have been an innovative means of building student knowledge inside and outside the classroom. These include Problem-Based Learning, Cooperative Learning, and Inverted Classroom. Such methods were used in association with investigative methods for teaching Chemistry at the Federal University of Ceará Campus Crateús in a repeating class. From this, the effectiveness of this method in comparison to the traditional classroom methodology was analyzed. In addition to the continuous and formative assessments carried out with the students, opinion questionnaires applied by the teacher and monitor were used to obtain the research data. After applying the hybrid method, students were consulted and the following data were observed: $83.3 \%$ were satisfied with their learning, $93.3 \%$ said they had their doubts resolved and $60.0 \%$ indicated they were less pressured about the form of evaluation. There is also a reduction in the number of dropout students (4.9\%) in the discipline when compared to traditional classes. Thus, it can be inferred that students have significant gains in conceptual understanding and skills addressed by the discipline of chemistry.
\end{abstract}

Keywords: Inverted classroom; Hybrid methodology; General chemistry. 


\begin{abstract}
Resumen
Las metodologías activas han sido un medio innovador para desarrollar el conocimiento de los estudiantes dentro y fuera del aula. Estos incluyen el aprendizaje basado en problemas, el aprendizaje cooperativo y el aula invertida. Dichos métodos se utilizaron en asociación con métodos de investigación para la enseñanza de la Química en la Universidad Federal de Ceará Campus Crateús en una clase repetida. A partir de esto, se analizó la efectividad de este método en comparación con la metodología tradicional de aula. Además de las evaluaciones continuas y formativas realizadas con los estudiantes, se utilizaron cuestionarios de opinión aplicados por el profesor y el monitor para la obtención de los datos de la investigación. Tras la aplicación del método híbrido se consultó a los alumnos y se observaron los siguientes datos: el 83,3\% estaba satisfecho con su aprendizaje, el 93,3\% dijo que tenía sus dudas resueltas y el 60,0\% indicó que estaba menos presionado en cuanto a la forma de evaluación. También debe considerarse una reducción de los estudiantes que abandonan la asignatura (4,9\%) en comparación con las clases tradicionales. Así pues, se puede deducir que los estudiantes presentan ganancias significativas en la comprensión conceptual y las habilidades abordadas por la disciplina de la química.
\end{abstract}

Palabras clave: Aula de reversión; Metodología híbrida; Química general.

\title{
1. Introdução
}

Cada vez mais a educação brasileira tem a necessidade de inovação nas metodologias de ensino e de pesquisa de forma imperativa, com urgência. Parte dessa inovação é resultado da velocidade e da fluidez com que informações são atualmente transmitidas, uma vez que os acadêmicos deste século, singularmente os do ensino superior, têm apresentado um comportamento incomum em sala de aula, em parte, relacionadas ao uso das tecnologias digitais de informação e comunicação (TDIC) (Cardoso et al., 2021; Valente et al., 2017).

Ao observar que o crescente processo de inovação nas metodologias de ensino tem a capacidade de produzir conhecimento independente de espaço e de tempo que aconteça. Todo progresso causa repercussão direta na educação, levando uma maior qualificação do professor e agregando novas competências e habilidades para o exercício da docência, isso enquadrando-se ao um novo modelo de sistema de ensino (Rodrigues et al., 2014).

Mesmo com um número expressivo de instituições de ensino superior (IES) brasileiras têm usado, de forma perdurável, o modelo tradicional de ensino como padrão, onde o professor expõe o conteúdo e os estudantes são passivos no processo de aprendizagem (Pavanelo \& Lima, 2017).

Segundo Britto et al. (2008), na última década ocorreu um processo denominado de "massificação do acesso" que se configurou no surgimento de um "novo discente". Para Oliveira et al. (2018), esses novos estudantes tendem a evadir-se por diferentes motivos. Ele menciona principalmente a "dificuldade em compreender o conteúdo lecionado" e consideram as "avaliações muito difíceis". Dessa forma, é incisiva a necessidade de redefinição e inovação de novas metodologias de ensino, que possam diminuir a problemática da evasão, da falta de interesse dos estudantes pelas aulas e, consequentemente, o alto índice de repetência, sobretudo em disciplinas das ciências exatas.

É conveniente considerar que as universidades são referência quando se trata da implementação de novas metodologias de ensino, uma vez que se presume que os estudantes possuem discernimento, adaptando-se com mais facilidade às abordagens pedagógicas inovadoras, ampliando, contudo, a efetividade destas (Suhr, 2016). Vale ressaltar que a metodologia tradicional de aulas expositivas pressupõe que todos os estudantes compreendem as informações transmitidas pelo docente em um mesmo ritmo (Milhorato \& Guimarães, 2016). Já na metodologia ativa, o docente pode disponibilizar materiais de ensino, como videoaulas e textos didáticos, por meio das TDIC, para que o estudante compreenda da maneira que considere mais adequada, promovendo um intercâmbio de conhecimento dinâmico e pensamento crítico entre estudantes e docentes (Suhr, 2016).

A metodologia ativa supracitada é designada Flipped Classroom, ou "Sala de Aula Invertida" (SAI), onde a temática e as orientações recebidas são estudadas on-line e antecedem aos encontros presenciais em sala de aula, usando como ferramentas as TDIC, mais notadamente, os ambientes virtuais de aprendizagem (AVA). Nesse sentido, constrói-se na sala de 
aula um ambiente para aperfeiçoar os conteúdos já estudados, exercitando, por meio de resolução de problemas e projetos, discussão em grupo e atividades práticas em laboratórios. É possível acrescentar que a metodologia da SAI comunga de alguns preceitos estabelecidos pelo sistema de aprendizagem colaborativa, trazendo outras facetas e detalhes a essa metodologia, pois é preciso entender que os elementos intrínsecos ao ensino possam ajudar na metodologia, no sentido de promover a motivação para a aprendizagem prévia, levando a um maior aproveitamento do tempo de orientação do docente em sala de aula (Almeida et al., 2020; Kasseboehmer \& Ferreira, 2013).

A metodologia da SAI como um meio inovador de construção de conhecimento e como proposta de ensino menos centralizado no docente não é recente e tem sido uma solução instituída nas melhores universidades do mundo, como a Harvard University e o Massachusetts Institute of Technology (MIT), nas quais algumas disciplinas já utilizam a abordagem (Park \& Howell, 2015; Pérez-Sanagustín et al., 2017). Nessa metodologia, é pertinente informar ainda que a parte presencial deve necessariamente contar com a supervisão do docente, valorizando as interações interpessoais, complementando, assim, às atividades de estudo individual prévio, proporcionando um processo de ensino e de aprendizagem mais eficiente, promovendo uma maior interatividade entre os estudantes e os docentes fortalecendo, as relações interpessoais, outrora escassas devido a vários fatores como aversão à disciplina ministrada e/ou o cansaço devido à extensa jornada acadêmica.

É cabível destacar que existem questionamentos a essa metodologia ativa, principalmente os relacionados ao conceito de inversão de uma sala de aula. Segundo Rodrigues et al. (2014), não existe um padrão para inversão de uma sala, pois cada situação traz para si suas problemáticas e particularidades. Seguindo essa linha de raciocínio, Honório (2017) relata falhas na metodologia dizendo, por exemplo, que o modelo depende bastante da tecnologia, acarretando uma certa desigualdade na aprendizagem, se relacionando tanto à motivação de cada um para estudar quanto ao acesso à informação. Tal ideia não pode ser descartada, pois a falta de interesse de muitos estudantes vem devido a diversos fatores como sequência de reprovações, falta de interesse por determinado assunto, dentre outros (Yamaguchi \& Silva, 2019).

A partir da visão de Sousa (2016) sobre a aprendizagem colaborativa (AC), esta poderia minimizar algumas falhas e contribuir com a metodologia de SAI, pois AC considera o estudante como elemento ativo no processo de aprendizagem, oferecendo a ele grandes possibilidades de desenvolvimento de competências sociais e cognitivas individuais.

Além da AC, o método conhecido como Aprendizagem Baseada em Problemas (ABP) pode complementar às falhas mencionadas na metodologia SAI, uma vez que a metodologia de ABP traz novas maneiras de repassar e fixar o conhecimento através de atividade científica que adapta a prática ao ambiente acadêmico teórico (Braga et al., 2021; Souza \& Dourado, 2015).

O ensino de Engenharia, dentro da Universidade, disponibiliza várias possibilidades de empregar as metodologias ativas de aprendizagem nas múltiplas áreas de formação profissional. Como exemplo, as aulas experimentais no laboratório, os trabalhos em equipe dentro e fora do ambiente acadêmico, as visitas técnicas, a elaboração de projetos, dentre outras. Essas ações são naturalmente participativas e proporcionam o envolvimento do estudante na evolução da aprendizagem.

Todavia, a vivência facilitada pelos métodos ativos nas atividades práticas vai de encontro a uma das grandes adversidades pedagógicas contemporâneas; integrar esses métodos no espaço e tempo atualmente ocupados pelas tradicionais aulas expositivas, pois é na sala de aula e nas relações interpessoais entre docente e estudantes, que as mudanças são mais urgentes e necessárias (Bonwell \& Eison, 1991).

O modelo pedagógico de sala de aula invertida foi, primeiramente, publicado por Lage et al. (2000) e popularizado por Bergmann e Sams em 2012, com a proposta de uma abordagem ativa de aprendizagem que visa melhorar a eficácia do aprendizado em sala de aula, permitindo que os estudantes controlem o tempo e o ritmo de aprendizado on-line e maximizem sua oportunidade de aprendizado ativo, por meio da participação nas discussões em sala de aula e nos exercícios colaborativos na companhia dos professores (Mok, 2014; Young, 2002). 
O uso desse modelo está crescendo em muitos campos da ciência, incluindo enfermagem (Magalhães et al., 2020; Njie-Carr et. al., 2017; Simpson \& Richards, 2017), medicina (Freitas et al., 2020; Chen et al., 2017), odontologia (Araújo et al., 2021; Crothers et al., 2017) farmácia (McLaughlin et al., 2014), saúde pública (Gomes et al., 2020; Howard et al., 2017; Galway et al., 2014) e ensino de engenharia (Barbosa et al., 2021; Gonçalves et al., 2020).

Estudos atuais utilizando métodos mais robustos de análise que confirmam as melhorias nos resultados da aprendizagem, embora moderados, com a utilização de metodologias ativas (Anderson \& Brennan, 2015; Calimeris \& Sauer, 2015). Indo além da análise de como a inversão de sala de aula afeta os resultados da aprendizagem em geral, alguns pesquisadores começaram a investigar questões mais refinadas. Ryan e Reid (2016) perguntaram como a mudança da sala de aula afeta os resultados dos alunos mais fracos e Touchton (2015) enfocou o tipo de aprendizado que a metodologia de sala de aula invertida afeta mais. Segundo Touchton (2015), há uma melhoria mais pronunciada nos resultados de aprendizagem nas disciplinas em que os estudantes consideram mais difíceis, embora o nível agregado das melhorias seja pequeno.

Olitsky e Cosgrove (2016) examinaram se os ganhos nos resultados de aprendizagem se tornam maiores à medida que os estudantes se adaptam à metodologia ativa e concluiu que os ganhos em aprendizagem aumentaram à medida que a utilização da supracitada metodologia progrediu e os estudantes tornaram-se mais seguros e conhecedores da nova abordagem pedagógica.

Os autores do livro A Rich Seam: How New Pedagogies Fund Deep Learning, Fullan \& Langworthy (2014), apontam algumas dificuldades impostas à essa metodologia que podem impedir ou desacelerar a sua implementação, como por exemplo a rigidez e a adequação das instituições a modelos que não foram validados, conforme as resoluções vigentes, como também a pouca informação sobre competências e as habilidades dos estudantes, em geral defasadas de um ensino médio precário, além da formação do docente, que não possui na sua carreira a preparação para esse tipo de atuação.

Todavia, os métodos de ensino onde os estudantes são proativos e protagonistas de seu próprio aprendizado possuem várias vantagens que os tornam viáveis sua implementação, inclusive no ensino superior. Segundo Valente (2015), tal fenômeno é viável graças ao desenvolvimento da tecnologia e da crescente disponibilidade de informações em todo lugar e tempo, além da facilidade de acesso a tais.

Focando principalmente na área de engenharia, Aqqal et al. (2017) cita que o objetivo do método ativo implementado com foco em engenharia tem sido o aprimoramento das habilidades e competências dos estudantes, com foco em:

1. Melhorar a comunicação dos estudantes de uma forma geral (oratória, conversação, exposição de ideias etc.);

2. Identificar, construir algoritmos e resolver problemas que envolvem a engenharia;

3. Ter visão não só acadêmica, mas também profissional sobre a solução dos problemas, envolvendo a economia, a comunidade, o meio ambiente, entre outros;

4. Desenvolver o trabalho em equipe;

5. Utilizar as novas tecnologias emergentes para a resolução das problemáticas propostas.

Assim, os estudantes estariam preparados para enfrentar uma maior série de desafios na vida acadêmica e no futuro mercado de trabalho, desde que sejam apresentados a metodologia ativa no princípio de sua formação. Fullan e Langworthy (2014) deixam claro o êxito na implementação em um sistema que anteriormente o ensino tradicional depende dos seguintes quesitos:

I. Gerar o ensino e as informações de formas diferentes, fazendo com que o maior número de estudantes possa absorvê-lo da sua maneira individual;

II. Disseminar tal metodologia adaptada para um grupo maior de indivíduos, um sistema no geral, alinhando assim toda a forma como a informação é transmitida naquele meio;

III. Ter um produto final competente, fazendo com que o estudante seja realmente capacitado a desempenhar as 
habilidades expostas durante seu curso, trazendo benefícios para ele, a instituição e a comunidade.

De toda forma, o sucesso de se utilizar as metodologias ativas conforme Biggs (2012), algo que depende tanto do docente como do estudante, pois este deve possuir ou construir, junto com o docente, a sua identidade e entender qual a melhor forma de aprender diferentes conteúdos, ao passo que o professor deve aplicar o que ele aprende sobre a personalidade de aprendizado de seus estudantes para adaptar a apresentação de seus conteúdos e trazer a melhor forma de exposição para cada um, alternando-a gradativamente.

Diante do exposto, o presente trabalho objetiva-se em aplicar a metodologia de SAI mesclada com o método ABP, jogos lúdicos e experimentação, em um ambiente de aprendizagem cooperativa, na disciplina de Química Geral dos cursos de Engenharia do campus da UFC em Crateús. Este método foi realizado em uma turma do segundo semestre de 2017, constituída por estudantes repetentes, alguns com até três reprovações consecutivas.

\section{Metodologia}

\subsection{Dados demográficos}

Os dados utilizados neste estudo de caso foram coletados no campus avançado da UFC em Crateús, recém implantado pelo processo de ampliação da Rede Federal de Ensino Superior com significativa propensão à evasão dos seus discentes, segundo Oliveira et al. (2018). A propensão à evasão citada pelo autor corrobora as taxas de insucesso (Figura 1) dos estudantes de engenharia matriculados em turmas de Química Geral, no período de 2015 a 2018. Esses dados foram levantados via Sistema Integrado de Gestão de Atividades Acadêmicas (SIGAA).

Figura 1 - Taxa de insucesso das turmas de repetentes de Química Geral no período de 2015 a 2018 (SIGAA).

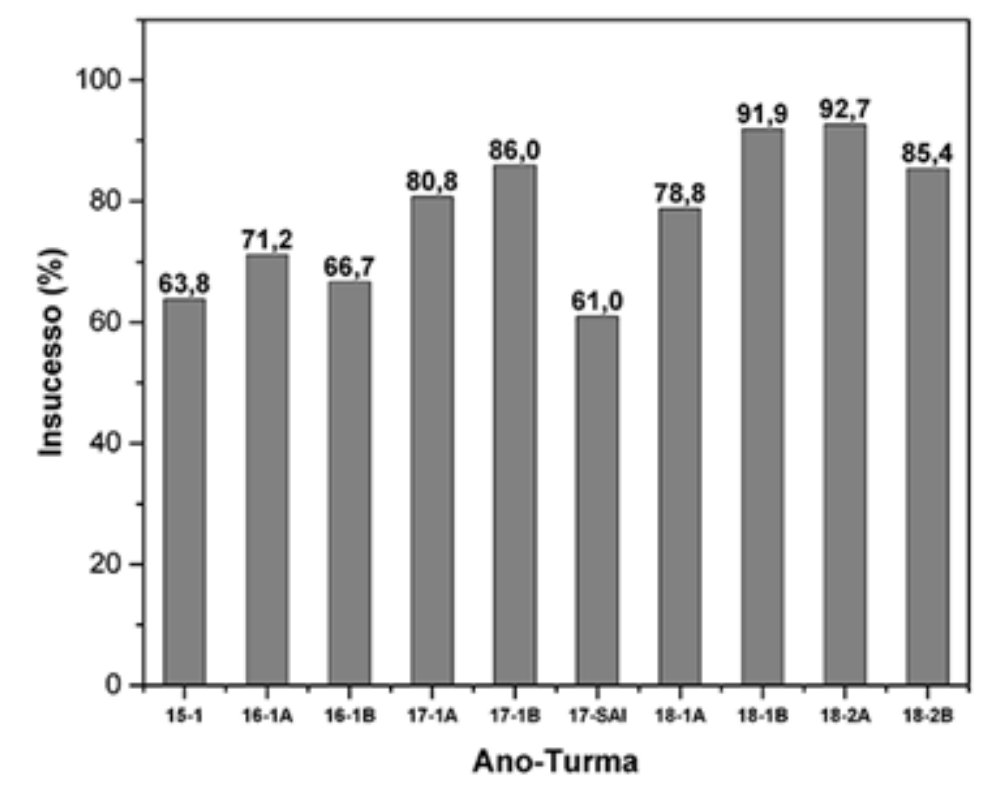

Fonte: Elaborado pelos autores (2018).

As taxas de insucesso apresentada na Figura 1 reforçam o indicativo de que a metodologia tradicional de ensino não tem apresentado êxito nas turmas de Química Geral da UFC campus Crateús. Diante do exposto, a turma amostral estudada neste artigo foi constituída por 39 (trinta e nove) estudantes (24 masculinos e 15 femininos) dos cursos de Engenharia da Universidade Federal do Ceará Campus Crateús, sendo todos repetentes da disciplina de Química Geral, com um tempo para a realização da coleta de dados de um semestre. 
Em síntese, a pesquisa consistiu em lecionar a disciplina Química Geral na forma combinada de metodologias ativas, desenvolvida com a utilização dos modelos de Sala de Aula Invertida (SAI), de Aprendizagem Baseada em Problemas (ABP), de método investigativo e de Aprendizagem Cooperativa (AC), com o objetivo de sugerir uma proposta pedagógica de ensino personalizada, além de comparar os resultados finais da turma investigada com os resultados de três semestres de turmas anteriormente e dois posteriormente ministradas por meio de aulas tradicionais, além de averiguar se há diferença nas taxas de insucesso e de satisfação dos estudantes nessa turma.

\subsection{Material Didático}

A metodologia utilizada consistiu em uma adaptação do princípio da SAI, e descreve a seguir os métodos de seleção e a forma de utilização do material didático, além da descrição da metodologia empregada.

Para o dimensionamento e a organização do material didático, cada tópico da ementa da disciplina foi composto por textos explicativos, criteriosamente selecionados pela docente da disciplina em sites da Internet, por listas de exercícios, provenientes de um banco de questões de propriedade da mesma e por livros (devidamente referenciados, tendo em vista o respeito aos direitos autorais). Os textos foram, em sua maioria, transcritos destinando à objetividade da leitura, por parte do estudante, e primando por garantir que houvesse uma sequência lógica do conteúdo. Os textos e os capítulos dos livros supracitados eram previamente enviados, via SIGAA, e esta atividade teve como objetivo em abranger os estilos reflexivo e verbal de aprendizagem.

Para cada encontro presencial, eram disponibilizadas listas-desafio, intentando estimular a necessidade de estudo prévio do conteúdo e a busca do conhecimento. Vale ressaltar que a turma em investigação era composta por estudantes repetentes e que os mesmos cursaram a disciplina utilizada neste estudo pelo método tradicional. Assim foi priorizado a utilização de jogos e práticas interativas, intentando minimizar a monotonia de estudar novamente um conteúdo já praticado.

\subsection{Proposta de Metodologia Mista da SAI mesclada com ABP e AC}

$\mathrm{Na}$ metodologia tradicional de ensino o docente planeja as suas aulas tendo como pressuposto a transmissão ativa e a absorção passiva do conhecimento. No método de sala de aula invertida, além da seleção criteriosa dos conteúdos compartilhados, o professor necessita dedicar-se excedentes horas no planejamento das aulas, intentando prever as intervenções necessárias a construção do conhecimento, considerando ainda a turma com intelecto heterogêneo, além de buscar a promoção do protagonismo no aprendizado dos estudantes.

Nos encontros presenciais os estudantes eram divididos em equipes com 10 membros. O plano de aula executado em cada encontro foi temporalmente dividido e encontra-se descrito a seguir:

- Introdução (20 minutos): acolhimento, sensibilização e tira dúvidas do material estudado em casa;

- Desenvolvimento (90 minutos): utilização de jogos de batalha com questões-desafio, jogos de tabuleiros, uso de experimentos, simulações, investigação de crimes com base na engenharia forense e resolução de problemas empresariais de engenharia;

- Conclusão (10 min): feedback do nível de assimilação e aprendizado, por meio de dinâmicas e/ou debate em grupo.

O desenvolvimento das atividades acima descritas é detalhado a seguir:

i) Questões-desafio: essa atividade foi associada a jogos de batalha entre equipes, intentando a busca das respostas por meio dos seus conhecimentos prévios ou da disseminação colaborativa do conhecimento. Essa atividade foi dividida em três etapas: a primeira equipe desafiada respondia às questões elaboradas pela docente e no segundo momento, as perguntas eram escolhidas ou elaboradas pelas demais equipes e para finalizar promovia-se um duelo entre a docente e as equipes. Durante todas as etapas a docente interviu fazendo outras perguntas ou aumentando o nível das mesmas. 
ii) Jogos interativos: a seguir os jogos utilizados nas aulas presenciais:

- Ludo Estequiométrico: adaptado de Zanon et al. (2008) que é caracterizado por ter o tabuleiro dividido em três níveis de dificuldades, onde as perguntas são qualitativamente refinadas a cada "casa limite" dos níveis. As pretensões desta atividade residem em identificar as deficiências pontuais dentro de cada grupo;

- Dominó das Ligações: adaptado de Santos \& Sarinho (2017) caracteriza-se por um jogo de 28 peças, sendo cada peça constituída por dois elementos químicos, com seus respectivos elétrons de valência, em cada lado. A manipulação das peças era executada por um representante de cada equipe e a cada jogada assertiva, ou seja, onde as peças escolhidas simbolizavam um tipo de ligação, a equipe tinha que ir ao quadro e representar cooperativamente três diferentes moléculas para o tipo de ligação formada no dominó;

- Telefone sem fio: o jogo consiste em transmitir verbalmente uma frase sobre determinado assunto. A intenção desse jogo é manter com mais precisão possível a integridade da frase verbalizada. Durante a transmissão da frase é possível corrigila e assim tentar transcrever a afirmativa de maneira correta.

iii) Método Investigativo/experimental: nesta atividade o estudante é instigado a propor soluções ou elaborar hipóteses para diversas ocorrências como o incêndio em uma fábrica de brinquedos. Para tanto, é disponibilizado experimentos com roteiros parciais de execução, além de informações extras. Estas informações pretendem "fortalecer" ou "enfraquecer" as hipóteses a serem descritas pelas equipes. As hipóteses propostas eram defendidas por cada equipe e coletivamente discutidas em sala. Os materiais disponibilizados para e execução dos experimentos são de baixo grau de toxicidade e de fácil acesso como: glicerina, bicarbonato de sódio, permanganato de potássio etc.

iv) Aprendizagem Baseada em Problemas: o método baseado em problemas segue as etapas descritas na Figura 2.

Figura 2 - Descrição das etapas do método baseado em problemas, adaptado de Borochovicius e Tortella (2017).

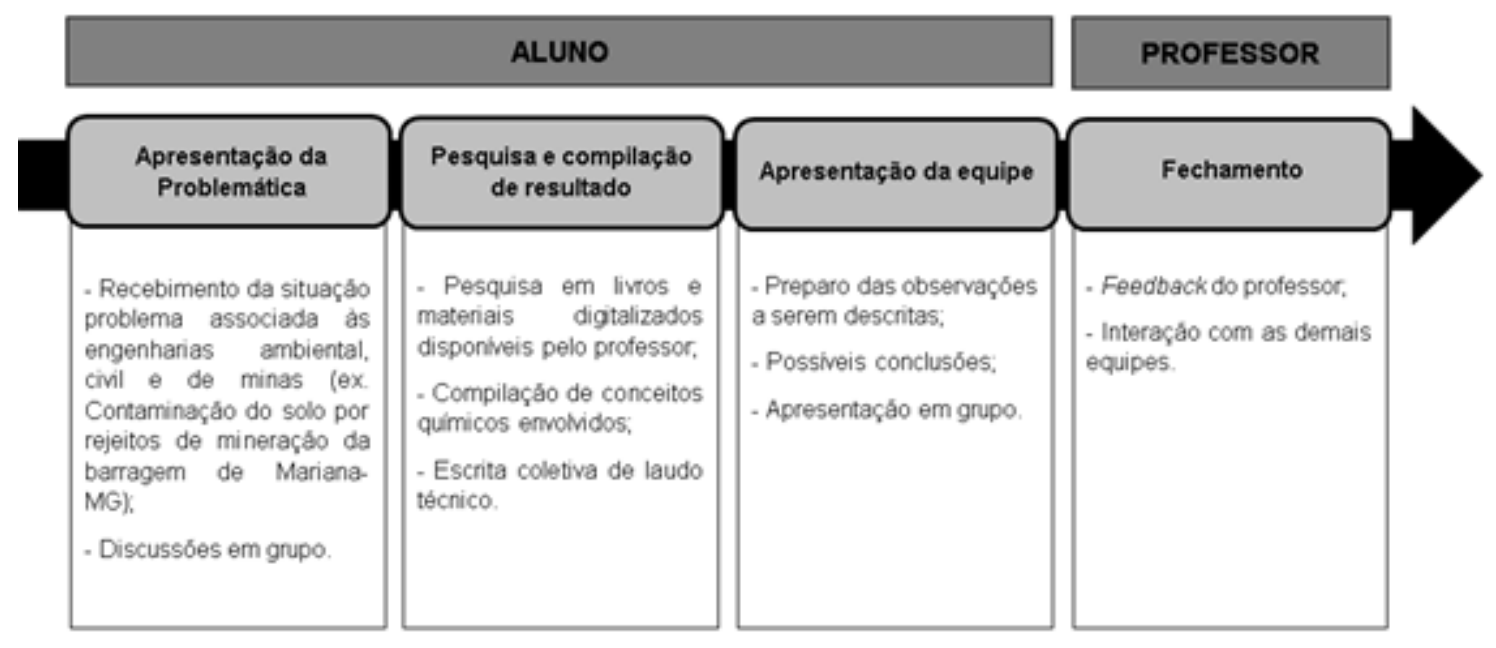

Fonte: Elaborado pelos autores (2018).

v) Simulações: para esta atividade utilizou-se o simulador disponível em https://phet.colorado.edu/pt_BR/simulation/acid-base-solutions.

A Figura 3 apresenta uma ilustração das etapas metodológicas híbridas utilizadas, Sala de Aula Invertida (SAI), Aprendizagem Baseada em Problemas (ABP), Aprendizagem Cooperativa (AC), Ensino Personalizado (EP), Instrução entre Estudantes (IE) ou entre pares e uso das Tecnologias de Informação e Comunicação (TIC). 
Figura 3 - Esquema representativo da metodologia ativa híbrida.

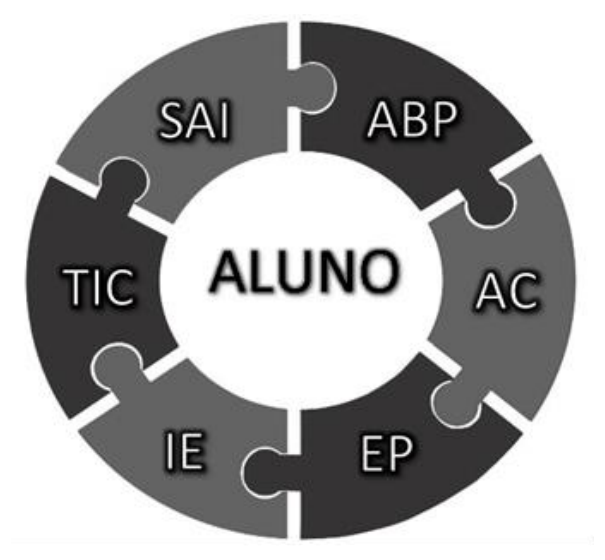

Fonte: Elaborado pelos autores (2018).

O delineamento das técnicas utilizadas e sua execução aos conteúdos ministrados estão descritas na Figura 4.

Figura 4 - Distribuição dos conteúdos e metodologias associadas a SAI.

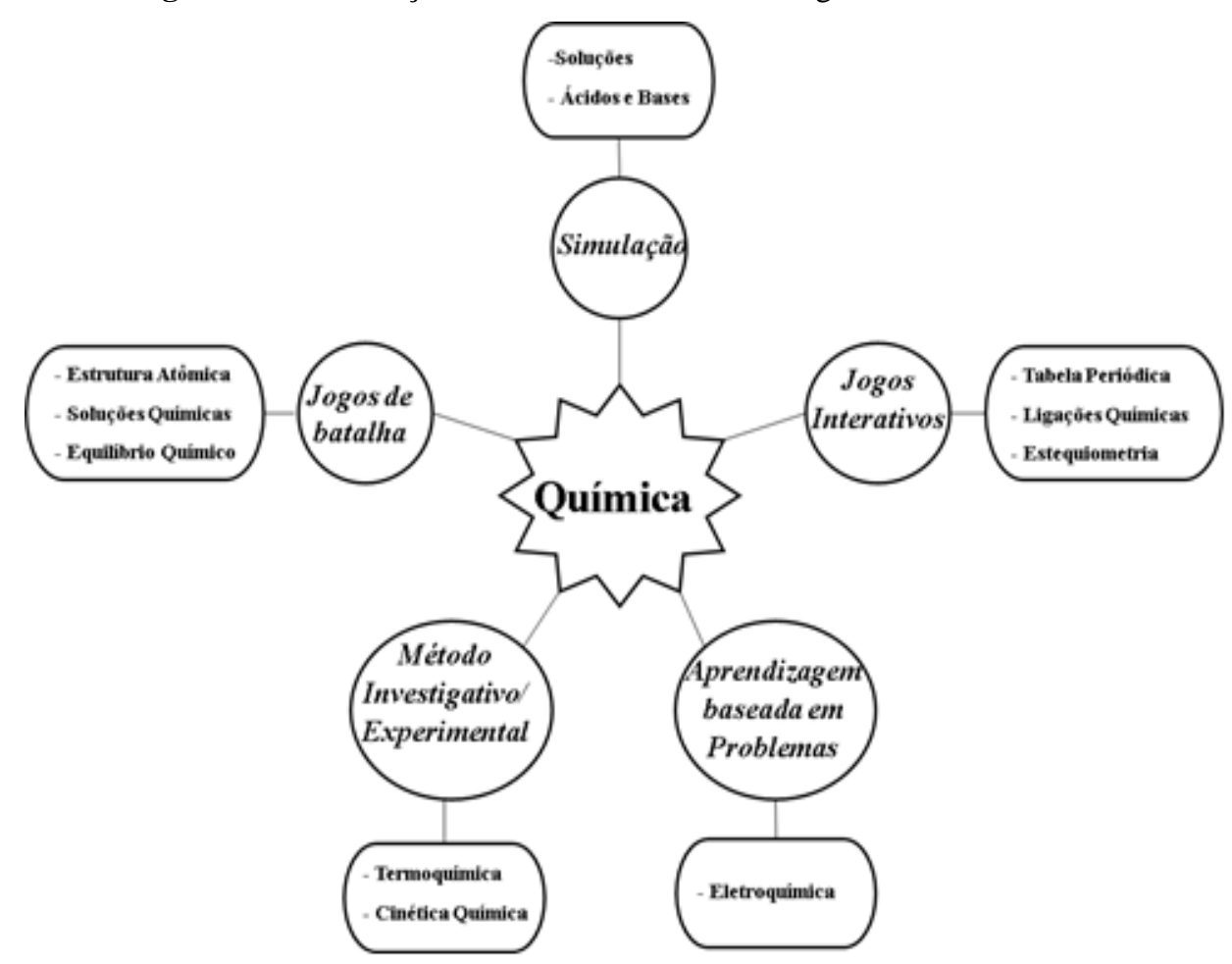

Fonte: Elaborado pelos autores (2018).

\subsection{Avaliação}

i) Avaliação do estudante: Duas avaliações compilaram o desempenho da turma: avaliação continuada (ACT) e avaliação formativa por meio de prova.

A ACT foi aplicada em todos os dias de aulas e os itens avaliados estão descritos na Tabela 1. Deve-se ressaltar que a Tabela é uma adaptação do método descrito por Bloom (1976) e Broietti et al. (2009). 
Tabela 1 - Ficha individual para a ACT.

FICHA DA AVALIAÇÃO CONTINUADA

Aluno

Matrícula

Curso

\section{Habilidades sociais}

\begin{tabular}{|c|c|c|}
\hline ASPECTOS OBSERVADOS & PONTUAÇÃO & OBSERVAÇÕES \\
\hline \multicolumn{3}{|l|}{ Participação } \\
\hline \multicolumn{3}{|l|}{ Compartilhamento de conhecimento } \\
\hline \multicolumn{3}{|l|}{ Trabalho em equipe } \\
\hline \multicolumn{3}{|c|}{ Habilidades cognitivas } \\
\hline ASPECTOS OBSERVADOS & PONTUAÇÃO & OBSERVAÇÕES \\
\hline \multicolumn{3}{|l|}{ Entendimento e fixação do conteúdo } \\
\hline \multicolumn{3}{|c|}{$\begin{array}{l}\text { Interdisciplinaridade do conteúdo } \\
\text { assimilado a outras disciplinas ou situações } \\
\text { do cotidiano. }\end{array}$} \\
\hline \multicolumn{3}{|c|}{$\begin{array}{c}\text { Utilização dos conhecimentos assimilados } \\
\text { em situações concretas da atuação } \\
\text { profissional }\end{array}$} \\
\hline \multicolumn{3}{|l|}{$\begin{array}{l}\text { Combinação de informações para a } \\
\text { construção do conhecimento }\end{array}$} \\
\hline Julga o valor do conhecimento & & \\
\hline
\end{tabular}

\section{TOTAL DE PONTOS}

Fonte: Elaborado pelos autores (2018).

A avaliação por meio de provas escritas foi elaborada com base nas discussões dos conteúdos em sala de aula, nos estudos colaborativos e tendo como base as listas de exercícios previamente enviadas (Honório, 2017). Foram realizadas 3 provas compostas de questões com a seguinte disposição do conteúdo: a) estrutura atômica, tabela periódica e ligações químicas. b) estequiometria, soluções químicas e termodinâmica c) cinética química, equilíbrio químico, ácidos e bases e eletroquímica.

Para avaliar as competências em provas formativas foi utilizado questões de situações-problema da vida profissional o que exigiu do aluno uma interpretação, planejar intervenções utilizando-se dos conteúdos de química e por fim avaliar os prós e os contras das intervenções. A resolução da questão estimula o aluno a expressar suas opiniões e defender ou argumentar sobre o problema disposto favorecendo também a discursiva crítica científica.

A nota do estudante foi calculada por meio da média aritmética entre as notas da avaliação continuada e as notas obtidas na avaliação escrita.

ii) Avaliação do método: Para avaliar o nível de satisfação dos estudantes, questionários de opinião foram aplicados objetivando obter dados relacionados à adaptação dos estudantes à metodologia ativa. 


\section{Resultados e Discussão}

\subsection{Vivências da docente sobre a metodologia mesclada de SAI}

Historicamente, dentro dos cursos de engenharia, a disciplina de Química Geral, possui dos índices de reprovação mais elevados seguidos por física e cálculo (Hora et al., 2018; Passos et al., 2007). Nos Projetos Pedagógicos dos Cursos de engenharia da UFC Campus Crateús, a disciplina de Química Geral é pré-requisito para diversas disciplinas dos cursos como Qualidade da água e controle da poluição, Ciência dos materiais, Materiais de construção civil e Físico-química. A reprovação nessa disciplina representa retenção, um atraso no cumprimento do currículo.

Por meio da avaliação institucional dos cursos de engenharia, emitida via SIGAA, foi possível verificar as principais dificuldades, críticas, fragilidades e sugestões a respeito da disciplina em questão. Entre os motivos apresentados pelos discentes para um alto índice de reprovação em Química geral pode citar um volume extenso de conteúdo, monotonia das aulas tradicionais apoiadas por slide e pouco tempo para resolução de exercícios.

Deve-se considerar ainda que há uma percepção de que os estudantes de engenharia apresentam uma resistência à disciplina, em decorrência da sua aplicabilidade à rotina profissional. Esta observação norteou o desenvolvimento das atividades pedagógicas, prevalecendo principalmente o compromisso no aperfeiçoamento das metodologias ativas que possibilitasse a evolução do estudante.

A escolha do método híbrido de SAI configurou-se na possibilidade de dinamizar e envolver os estudantes, tornandoos protagonistas do seu próprio aprendizado. No entanto, a inversão da sala de aula para as disciplinas do campo das exatas não é trivial, uma vez que exige do estudante uma maior capacidade de correlacionar o abstrato e vislumbrar o concreto.

Nesse sentido surgem alguns questionamentos a respeito da metodologia proposta:

1. Como dimensionar as atividades nos encontros presenciais?

2. Como estimular a leitura dos materiais dispostos na plataforma?

3. Como proceder no planejamento das aulas?

4. Como estimular o pensamento crítico do estudante e como proceder o aumento gradativo das atividades?

5. Como guiá-los no aprendizado por meio de suas respostas?

6. Qual o modelo ideal para se inverter a sala de aula?

É evidenciado que há a necessidade de adaptação da metodologia de SAI a cada disciplina a ser executada. Nesse sentido, vale esclarecer que o planejamento de uma aula no modelo SAI acontece em três etapas: $1^{\text {a: }}$ seleção adequada do nível e do tipo de material a ser disponibilizado na plataforma; $2^{\text {a }}$ : seleção acurada das atividades desenvolvidas no encontro presencial; $3^{\text {a }}$ : disponibilidade do docente para proceder o feedback, além da proposição de atividades complementares. Partindo desse princípio, a disciplina de Química, por ter uma ementa bastante extensa, foi ministrada em quatro horas semanais, distribuídas em dois dias. É evidente que para o sucesso do método proposto é necessário um maior tempo de planejamento das aulas.

Os estudantes participantes dessa amostragem levaram cerca de três semanas para adaptar-se ao método e nesse período foi constatado que os mesmos não realizavam a leitura prévia do material, fato este que dificultou as discussões, culminando no baixo nível dos questionamentos. Para superar essa fase de adaptação foi aplicado um jogo de batalha entre equipes, com o intuito de estimular a leitura prévia. É necessária cautela ao se utilizar essa estratégia, evitando o incentivo a concorrência entre equipes e promovendo o respeito e a individualidade da construção do conhecimento.

O jogo de batalha foi realizado em duas etapas: inicialmente as perguntas eram realizadas pelas equipes de estudantes e na segunda etapa eram elaboradas pela docente.

A heterogeneidade da turma quanto ao domínio dos conteúdos norteou a adequação do método. Observou-se que os discentes possuíam níveis diferentes de conhecimentos prévios necessários para o desenvolvimento a disciplina da química 
como regra de três, multiplicação e divisão de expoentes e distribuição eletrônica. Com a tentativa de igualar os conhecimentos básicos foram preparados materiais com etapas gradativas de informações e dificuldades, porém, a não leitura provocou um desconforto em sala. Tal desconforto foi, por vez, sanada pelo aprendizado cooperativo.

O aprendizado cooperativo (AC) exigiu do discente habilidades como saber ouvir, interagir, dividir conhecimento, participar de discussões e aceitar as diferenças. O AC teve também sua importância quanto a logística de atendimento individualizado por parte do professor e do aluno monitor uma vez que, a quantidade de alunos participantes compreendeu entre 38 e 50 alunos do início ao fim da disciplina. Esta variação na quantidade de alunos cursistas corresponde a $34 \%$ de desistências da disciplina onde os fatores envolvidos podem ser descritos como: quantidade de disciplinas matriculadas, priorização de outras disciplinas e ausência do hábito de estudar anteriormente as aulas. No entanto o aumento da sinergia entre os participantes e o professor por intermédio do AC que favoreceu a inclusão e ajudou na solidez de um grande grupo, agora, apto a progredir e se beneficiar com outros métodos ativos associados com a SAI.

Para incluir os jogos interativos na metodologia SAI foi necessário o amadurecimento dos alunos quanto ao método para que dentro do contexto cognitivo pudesse extrair o conhecimento e se projetar para aplicabilidade quanto a interdisciplinaridade e vida profissional.

O uso de jogos interativos nos conteúdos de tabela periódica, ligações químicas e soluções só foi possível após a adequação dos jogos ao ensino superior. Nesta etapa a ajuda do monitor foi indispensável principalmente na busca de jogos aplicáveis. Esta atividade possibilitou atingir os alunos os quais seu canal receptor é o visual proporcionando a percepção do abstrato de forma concreta. A intervenção do professor nesta atividade está em apresentar a ligação entre macroscópico e o concreto e, microscópico/abstrato através do jogo, ressignificando o aprendizado e os conteúdos.

Apesar de uma grande contribuição dos jogos no contexto do aprendizado via SAI, a disciplina também exige habilidades investigativas nas quais são vivenciadas através das hipóteses. A investigação laboratorial ajudou nas respostas das hipóteses, estimulando o senso crítico e argumentativo do aluno. Este método foi desenvolvido para contribuir com os estudos de termodinâmica e cinética química. A equipe recebeu um conjunto de hipóteses a serem discutidas e um roteiro bem simplificado que funcionava como pistas da investigação. O desafio da equipe compreendia em solucionar as hipóteses lançando mão das pistas e dos utensílios disponíveis para execução do experimento. Ao finalizar a equipe apresenta a solução das hipóteses encontradas, e os demais grupos puderam opinar completando ou refutando integralmente ou parcialmente os relatos da equipe propositora.

Os experimentos que apoiam as hipóteses termodinâmicas possibilitaram verificar alguns fenômenos como transferência de calor, capacidade térmica, energia interna, entalpia e entropia. Os experimentos que deram suporte às hipóteses cinéticas passando por conceitos de reação química, velocidade da corrosão e fatores que afetam a velocidade reacional.

O método exigiu que o aluno fosse além do material disponível na plataforma SIGAA para apoiar suas observações. A tomada de decisão sobre os caminhos investigativos a serem usados abriram o leque de opções que resultaram em soluções factíveis aos problemas expostos. Ao tentar pensar em quais alternativas plausíveis para a resolução da hipótese e problemática disponível o aluno entra em um processo reflexivo, por vezes coletivo, para ao final chegar a conclusões sobre o observado. $\mathrm{Na}$ busca de respostas e explicações para fenômenos e, em meio ao processo reflexivo, o discente desenvolveu habilidades experimentais que, discutido dentro próprio contexto químico, proporciona a construção de um quebra cabeça cognitivo o qual finda com o aprendizado do estudante. A experimentação desenvolveu um elo entre a curiosidade, conhecimento químico, habilidades práticas, poder discursivo, domínio de sequência lógica na resolução de problemas e o cotidiano produzindo uma fórmula quase mágica de fixação da atenção no conteúdo. Nesta etapa foi evitado dar respostas prontas e optou-se por fazer questionamentos motivadores que auxiliam na conclusão da problemática. 
O conteúdo de ácidos e bases e parte de soluções químicas foram ministrados através de uso de simuladores. O uso do simulador titulométrico bem como o de preparo de soluções gerou um grande interesse por parte dos alunos. O planejamento para esta atividade compreendeu em extrair os conceitos como força dos ácidos e das bases, concentração de soluções, soluções tampões e equilíbrio. Para viabilizar o uso do simulador foi disponibilizado um computador e data show para ampliar as informações do software. As equipes receberam um texto contextualizando as análises, e ao irem ao computador as mesmas puderam verificar se seus cálculos eram coerentes com os disponíveis através da simulação. Também foi possível através do simulador o conhecimento de vidrarias e verificação do erro experimental. Deve-se enfatizar que o uso da tecnologia simplesmente por usar, não envolve o aluno nas sentenças necessária para o aprendizado e a proposta fica comprometida.

A última metodologia ativa a contribuir com o método híbrido foi o aprendizado baseado na problemática. A eletroquímica é bastante usada na engenharia e seus conceitos usados em diversas disciplinas. Assim para abordar este tema com base na problematização foram criadas empresas hipotéticas com problemas envolvendo a eletroquímica. A primeira problemática referiu-se a metais pesados descartados em ambientes aquáticos por uma mineradora. $\mathrm{O}$ aluno deveria propor técnicas eletroquímicas para melhorar a eficiência da empresa em reter os metais pesados reduzindo significativamente sua presença na água de rejeito. A segunda solução problema referia-se a uma construtora que teve problemas com corrosão do concreto. Os alunos deveriam investigar que tipo de pilha estaria atuando na corrosão e como sanar tal problema.

Em todo o percurso o aluno tinha a sua disposição materiais anexados à plataforma SIGAA e livros disponíveis na biblioteca. Ao sanar e propor uma solução para as empresas a equipe relatava para os demais o caminho percorrido para obter as respostas e discutir coletivamente os acertos, erros e caminhos alternativos. A intervenção do professor é de mediador e de possibilitar reflexões sobre o assunto. A dificuldade com a abordagem baseada em problema é a adequação do problema/hipótese do assunto estudado e exigido pelo currículo e o nível de conhecimento dos alunos.

Por fim pode-se dizer que todos os métodos possuem seus benefícios e dificuldades e a eficiência só é evidenciada quando se avaliada o sistema como um todo. A avaliação continuada do aluno também reflete na eficiência do método. Isto é, se o planejamento e a aplicação do método forem satisfatórios o aluno apresentam-se mais interessados e interage mais rápido com o conteúdo e com os colegas. $\mathrm{O}$ aprendizado flui sem maiores empecilhos.

\subsection{Vivência do estudante monitor}

A experiência de vivenciar uma metodologia personalizada e inovadora é sem dúvida algo enriquecedor, pois é perceptível que possibilita ao estudante uma forma de adquirir conhecimento a um nível mais elevado e personalizado, aprendendo assuntos, que anteriormente foram considerados muito complicados, de forma mais simples e proveitosa.

O método híbrido de SAI possibilita muitas vantagens e benefícios à vida acadêmica dos estudantes, do monitor e dos docentes envolvidos. Nessa perspectiva, foi imprescindível a participação ativa do monitor.

Como informado anteriormente, a disciplina de química geral possui altos índices de reprovação. Partindo desse pressuposto, o monitor desempenhou um aspecto fundamental em auxiliar a professora na implementação dos diferentes métodos aplicados e ajudar os alunos da disciplina a alcançarem sucesso no desenvolvimento de seu conhecimento. Inicialmente, o proposto seria ajudá-los com tira-dúvidas em monitoria e práticas laboratoriais. Porém, ao ser desenvolvido o plano de ações para a disciplina baseada em metodologias ativas, notou-se a necessidade de uma participação também ativa do monitor, tanto fora como também dentro da sala de aula.

Além do acompanhamento dos alunos em sala de aula, o monitor se dedicou ao acompanhamento das aulas disponibilizadas na plataforma juntamente com o professor. No entanto foi observado um aumento da procura do monitor em turnos diferentes das aulas. Esta procura, inicialmente, estava vinculada a busca de respostas prontas de atividades virtuais ou presenciais. Orientado pela professora para não responder prontamente, o monitor vivenciou a responsabilidade de guiar os 
alunos em busca de suas respostas e sanar certas dúvidas que não podiam esperar para o momento da aula. A monitoria passou a ter dois horários distintos, um para acompanhamento individual e outro com acompanhamento em grupo para que fosse respeitada a individualidade do aluno e ao mesmo tempo fosse realizado o nivelamento dos conhecimentos.

Desse modo, o monitor viabilizou o intercâmbio de conhecimento, ao passo que trocavam informações e faziam com que também experiências de semestres e cursos distintos fossem levadas em conta. Foi notado que tais fatos fizeram com que os alunos conquistassem um amadurecimento necessário para obter as competências exigida para a disciplina e para os cursos de engenharia.

Observou-se ainda que ao decorrer do semestre os alunos estavam mais adaptados ao método, e a procura e o momento de tira-dúvidas com o monitor passou a ser mais dinâmica. Os alunos passaram a ir à monitoria não mais atrás de buscar respostas prontas, mas sim com dúvidas consistentes, embasadas no que foi estudado posteriormente. A mistura dos métodos os deixava fora da zona de conforto, especialmente o método da Aprendizagem Baseada em Problemas. A respostas exigiam dos estudantes pesquisas fora dos livros de química e conversas com professores de outras disciplinas e cursos, o que favoreceu a interdisciplinaridade e a sinergia entre eles.

$\mathrm{Na}$ tentativa de reduzir a competitividade entre as equipes de forma não saudável e desenvolver cooperatividade entre os estudantes, o monitor realizou junto a professora a adaptação dos jogos do ensino médio para o ensino superior. O desafio foi repensar o jogo vislumbrando a ementa do curso de química geral e ao mesmo tempo enxergar sobre as perspectivas do estudante enquanto, ainda, aluno.

No dominó químico o encaixe das peças predizia o número de ligações entre os compostos químicos, mas as propriedades químicas e física de cada elemento norteiam o tipo de ligação e a força entre os átomos. Assim construir a adaptação do jogo de dominó necessitou de regras que a equipe deveria executar ao encaixar as peças e garantir o aprofundamento como por exemplo, conceitos de energia de rede e orbital molecular.

O jogo de tabuleiro, ludo químico, foi organizado para conter níveis de dificuldades diferentes em cada etapa. Com auxílio da professora foi possível identificar as falhas do aprendizado quanto a regra de três, dificuldade de interpretação das questões e, consequentemente, dificuldade em extrair da questão os resultados. Foi possível identificar ações empáticas entre os colegas nas equipes e desta forma vivenciar a alegria dos pares em aprender.

A investigação experimental forneceu à turma curiosidade, um estímulo importante ao fim do semestre. Unir o aprendizado teórico a prática estimulou as discussões e a compreensão de alguns fenômenos cotidianos importantes para a continuidade do curso. Durante a experimentação com o vinagre e o bicarbonato, por exemplo, os alunos puderam absorver de modo prático as diferentes velocidades de reação e intercalar com conhecimentos de reagente limitante nas mesmas. Os alunos ficaram impressionados como a experiência e o aprendizado de cinética química que pode ser utilizado apenas alguns materiais encontrados no supermercado ou lojas de construção no local onde vivem.

A elaboração e a escolha de experimentos a serem realizados em sala de aula transitam pela concentração dos produtos, toxicidade e viabilidade de execução. Além disso, quando se pensa na usabilidade pelos próprios alunos é necessário um roteiro simples e curto que possibilite uma compreensão passiva de argumentação e contextualização com a hipótese.

As metodologias adotadas foram de grande ajuda na construção pessoal, acadêmica e pode-se dizer também profissional do monitor, deixando o mesmo com vontade de seguir a carreira acadêmica.

\subsection{Vivências do aluno cursista sobre a SAI}

A vivência dos alunos cursistas com o SAI foi estudada através de questionário aplicados no decorrer e após a disciplina.

A Figura 5 apresenta a perspectiva do aluno cursista quanto ao método e sua aprendizagem. Aproximadamente 36,7\% 
dos alunos relataram melhoria de seu aprendizado através do método híbrido e 56,7\% descreveram que o método foi uma boa ferramenta para o aprendizado. Aproximadamente 6,7\% dos alunos mostraram-se indiferentes quanto ao método e nenhum aluno relatou que o método foi ruim.

Figura 5 - Opinião dos alunos sobre a influência do método híbrido no seu aprendizado.

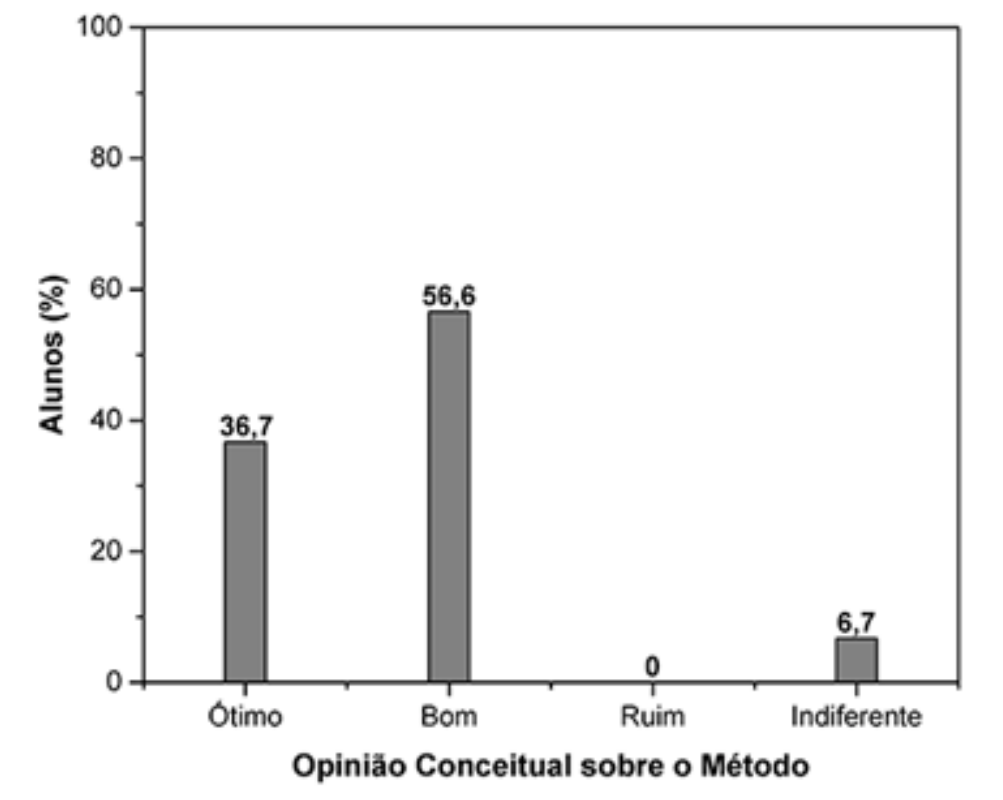

Fonte: Elaborado pelos autores (2018).

Nota-se que apesar da maioria dos alunos avaliarem o método positivamente, um pequeno percentual com indiferenças torna-se meta para melhoria. O docente deve lançar mão destes dados e formular novas estratégias para as aulas permitindo manter o interesse e a dedicação de todos os alunos.

A Tabela 2 apresenta o resultado da pesquisa com os cursistas quanto a satisfação de ter suas dúvidas sanadas, pressão na avaliação, eficiência do método no aprendizado e acessibilidade do material disponibilizado na plataforma.

Tabela 2 - Respostas em percentagem de sentenças afirmativas com respostas de sim/não.

\begin{tabular}{clc}
\hline Sentenças avaliadas & \multicolumn{2}{c}{ Valores (\%) } \\
\hline Dúvidas sanadas em sala de aula & Sim & Não \\
Método é eficiente e influência na aprendizagem & 93,3 & 16,7 \\
Acessa o material disponibilizado & 83,3 & 42,3 \\
Menor pressão quanto à forma de avaliação & 56,7 & 40,0 \\
\hline
\end{tabular}

Fonte: Elaborado pelos autores (2018).

Os estudantes entrevistados relataram que o método reduziu a distância entre aluno e professor, e que este, como facilitador em sala traz muito mais benefícios a sequência de aprendizado do que apenas como expositor de assuntos. Esta afirmativa também foi evidenciada por Galindo e Badilla (2016) fortalece a ideia de que a mudança da concepção do aluno em 
relação ao protagonismo de seus estudos favorece o aprendizado.

A propósito desta prerrogativa, cerca de $93,3 \%$ dos estudantes entrevistados, mostraram-se satisfeitos em relação as dúvidas sanadas. E embora a avaliação do método apresente apenas 36,7\% de satisfação aproximadamente 83,3\% mostraramse satisfeitos com seu aprendizado. Deve-se ressaltar que este questionário foi realizado inclusive com os alunos que não obtiveram rendimento satisfatório para a aprovação na disciplina indicando que os mesmos avaliaram positivamente seu aprendizado.

Visando buscar evidências quanto a interferência do estado emocional durante as provas o questionário perguntou aos alunos sobre a pressão durante a avaliação e $60,0 \%$ dos investigados apontaram para a redução da pressão durante as provas. $\mathrm{O}$ fato é que com a avaliação continuada o professor consegue visualizar o desempenho do aluno e as competências exigidas pela disciplina.

A acessibilidade ao conteúdo disposto na plataforma foi analisada e 56,7\% dos discentes apontaram ter acesso. No entanto uma margem ainda alta, cerca de $42,3 \%$ dos alunos descreveram ter dificuldade ao acesso. Na tentativa de aprofundar a dificuldades dos alunos no acesso foi adicionado ao questionário espaço para descrever as dificuldades e entre as mais indicadas estavam a internet ruim, tempo para acessar o material fora das aulas e mídia não apropriada para abrir e baixar os arquivos. A dificuldade de acessibilidade do material, de certa forma, prejudicou o andamento das atividades presenciais e, muito embora a não leitura do material prejudique principalmente quanto às dúvidas. Embora a falta de estudo prévio provocado pela dificuldade no acesso do material os dados mostram que, de uma forma geral, os alunos tiveram suas dúvidas sanadas.

Ao comparar o desempenho do aluno pela avaliação continuada e por provas tradicionais observa-se uma discrepância entre as notas, certamente devido ao formato avaliativo, ou seja, as notas da avaliação continuadas foram maiores que as apresentadas nas provas escritas. No entanto a avaliação continuada trouxe ao professor uma melhor visão sobre habilidades e competências importantes para a vida profissional as quais estão relacionadas com a disciplina. É importante ressaltar, ainda que, ao reencontrar alunos avaliados por este método em disciplinas mais avançada como qualidade da água e controle da poluição e físico-química o professor observou maior afinidade dos mesmos com abstração de conteúdos e aplicabilidade.

Na Figura 6 são apresentados os resultados das aprovações, reprovações por nota e falta, bem como a quantidade de desistentes da turma em que foi aplicada o método híbrido da SAI. Observa-se que praticamente metade dos alunos que continuaram na disciplina até o fim, conseguiram sucesso da aprovação, a saber, 41\% dos 39 matriculados. Verifica-se também que a taxa de reprovação por falta é de 13\% representando um quantitativo razoável em comparação com turmas tradicionais do Campus da UFC em Crateús. Entre os motivos apresentados para a reprovação por falta estão o desânimo de estar em uma turma de repetentes e o cansaço de aulas noturnas. O percentual de desistentes foi de 4,9\% considerada uma das mais baixas comparadas com as de semestres em que foi ministrada aulas no método tradicional. 
Figura 6 - Quantidade de alunos aprovados, reprovados por nota e falta e desistentes de 2015 a 2018.

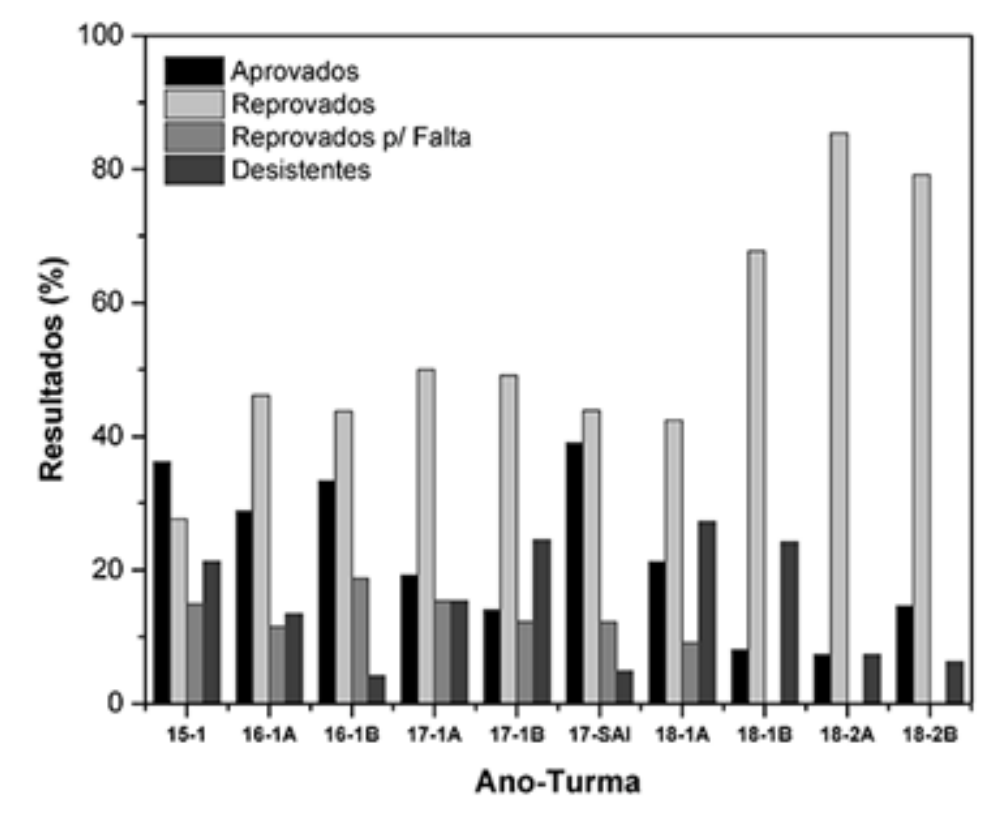

Fonte: Elaborado pelos Autores (2018).

Pode-se inferir ainda que os resultados de aprovação obtidos para esta turma em que foi aplicado o método híbrido da SAI comparados com os obtidos pelas turmas com métodos tradicionais são positivos. Observa-se ainda que em semestres posteriores em que o ensino tradicional voltou a ser ministrado houve uma redução das aprovações e um aumento das reprovações por nota e falta.

Mudar o que está sendo feito há tantas décadas exigirá uma mudança de postura não só dos professores, mas também dos alunos. Sabe-se que o método não é perfeito e que precisa de melhorias para adequar-se às necessidades do curso e da disciplina.

\section{Conclusão}

O método híbrido da SAI junto ao método Aprendizagem Baseada em Problema, jogos lúdicos e experimentação, em um ambiente de aprendizagem cooperativa tornou a disciplina de química menos cansativa e mais contextualizada com a vida profissional do futuro engenheiro.

A metodologia híbrida de ensino tem se mostrado um importante e eficaz meio pelo qual a aprendizagem dos alunos é consolidada. O estudo em grupo, o auxílio do monitor e as diversas atividades realizadas mantiveram aqueles alunos com dificuldade no aprendizado no mesmo ritmo da turma, fazendo com que as diferentes formas de ensino convergem para o bom rendimento geral.

Após a aplicação do método durante a disciplina de Química Geral na UFC Campus Crateús, a forma de ensinar e aprender tanto a do professor como a dos alunos foi renovada, fazendo com que estes se sentissem peça fundamental do aprendizado.

Com o planejamento do método bem como sua aplicabilidade, exige do professor uma maior dedicação na elaboração das aulas para manter o aluno empolgado e envolvido é sempre o desafio do professor, isso requer intimidade com a disciplina e com as habilitações necessárias para a vida profissional do futuro engenheiro.

$\mathrm{Na}$ implantação do método a presença do monitor foi fundamental, sendo o mesmo a extensão do professor nas atividades divididas e também na aplicabilidade do método junto com o professor, isso fez tornar o aluno monitor um 
profissional mais preparado, estimulando-o a seguir também a carreira acadêmica.

Foi observado uma discrepância entre a avaliação continuada e a avaliação por provas escritas tradicionais. No entanto a avaliação continuada trouxe ao professor uma melhor visão sobre habilidades e competências que são importantes para a profissão ao contrário da prova escrita mostrou a capacidade de compreensão, interpretação e expressão do aluno quanto aos conteúdos de química geral. Também mostrou a dificuldade em criar questões menos formativas e mais com mais competências para que ambas se complementam.

$\mathrm{Na}$ análise dos dados obtidos por questionários aplicados aos alunos cursistas verificou-se que 83,3\% dos alunos matriculados mostraram-se satisfeitos com seu aprendizado e que cerca de 93,3\% dos estudantes afirmaram ter suas dúvidas sanadas.

Essa resposta ao questionário indicou que 60,0\% dos alunos apresentaram-se menos pressionados quanto a forma de avaliação. Foi observado que $41 \%$ de uma turma de 39 alunos matriculados na disciplina obtiveram aprovação com o novo método. A taxa de reprovação por falta foi de $13 \%$ a qual representa um quantitativo razoável comparando com turmas de ensino tradicionais do campus da UFC em Crateús. O percentual de desistentes foi de 4,9\% considerando uma das mais baixas quando comparadas ao observar as demais turmas com ensino tradicional, não interferindo no aumento da desistência devido ao método.

Através do método foi verificado que os estudantes apresentam ganhos significativos na compreensão conceitual, bem como no ganho de habilidades para resolver problemas comparáveis aos adquiridos nas aulas tradicionais.

Para trabalhos futuros, planeja-se adaptar uma maior diversidade de jogos e experimentos para contribuir com os diferentes níveis de aprendizado dos alunos em sua própria casa, de forma prática e segura. Tal análise poderá verificar também a adaptação das metodologias ativas utilizadas anteriormente em sala presencial para o atual ensino remoto.

\section{Referências}

Almeida, A. C. F. de, Lopes, L. F. de O., \& Braga, C. B. (2020). Inovação Metodológica no Ensino: um recorte a partir das concepções dos professores de um instituto federal. Research, Society and Development, 9(7), e127973993. https://doi.org/10.33448/rsd-v9i7.3993

Anderson, L., \& Brennan, J. P. (2015). An experiment in flipped teaching in freshman calculus. Primus, 25(9-10), 861-875.

Aqqal, A., Elhannani, A., Haidine, A., \& Dahbi, A. (2017). Improving the teaching of ICT Engineering using Flipped Learning: a personalized model and a case study. Production, (27), 1-16.

Araújo, D. d. C., Almeida, C. P., Santana, L. R. P., Mota, S. B., Santos, A. D. d., Lima, S. V. M. A., Araújo, K. C. G. M. d., Alves, J. A. B., \& Vaez, A. C. (2021). Qualidade de vida dos estudantes da área da saúde que utilizam metodologia ativa de ensino-aprendizagem. Research, Society and Development, 10(5), e15410514737. https://doi.org/10.33448/rsd-v10i5.14737

Barbosa, J. B. M., Mendonça, F. J. S. de F., Tavares, F. R. M., Figueredo, J. F. de S., \& Leite, M. J. F. (2021). Utilização de impressoras 3D para o desenvolvimento de metodologias ativas em cursos de Engenharia. Research, Society and Development, 10(10), e181101018657. https://doi.org/10.33448/rsdv10i10.18657

Bergmann, J., \& Sams, A. (2012). Before you flip, consider this. Phi Delta Kappan Magazine, 94(2), 25.

Biggs, J. (2012). What the student does: teaching for enhanced learning. Higher Education Research \& Development, 31(1), 39-55, DOI: $10.1080 / 07294360.2012 .642839$

Bloom, B. S. (1976). Taxonomia dos objetivos educacionais 1 - Domínio Cognitivo. Editora Globo.

Bonwell, C., \& Eison, J. A. (1991). Active learning: creating excitement in the classroom. ASHE-ERIC Higher Education Reports, 1-121.

Borochovicius, E., \& Tortella, J. C. B. (2017). Problem-Based Learning: a method of teaching and learning and their educational practices. Ensaio: Avaliação e políticas públicas em Educação, 22(83), 263-294.

Braga, I. A. F., Maroneze, L. R., Carvalho, K. V. G. d., Moura, F. R. d., Santos, P. L. d., \& Tavares, D. dos S. (2021). Avaliação do temperamento afetivo e emocional em estudantes universitários da metodologia ativa de ensino. Research, Society and Development, $10(6)$, e17110615635. https://doi.org/10.33448/rsd-v10i6.15635

Britto, L. P. L., Silva, E. O., Castilho, K. C. d., \& Abreu, T. M. (2008). Knwoledge and education in the peripheral higher education institutions: profile of the "new" undergraduate student. Avaliação, 13(3), 777-791. 
Broietti, F. C. D., Barreto, S. R. G., \& Mendes, L. C. (2009). Estudo do desempenho dos candidatos nas Provas de química da segunda fase do Vestibular da UEL. VIII Encontro Nacional de Pesquisa de Educação em Ciências, Campinas.

Calimeris, L., \& Sauer, K. M. (2015). Flipping out about the flip: all hype or is there hope? International Review of Economics Education, (20), 13-28.

Cardoso, R. M. R., Araújo, C. S. T., \& Rodrigues, O. S. (2021). Tecnologias Digitais de Informação e Comunicação - TDICs: Mediação professor-alunoconteúdo. Research, Society and Development, 10(6), e45010615647. https://doi.org/10.33448/rsd-v10i6.15647

Chen, F., Lui, A. M., \& Martinelli, S. M. (2017). A systematic review of the effectiveness of flipped classrooms in medical education. Medical Education, 51(6), 585-597.

Crothers, A. J., Bagg, J., \& Mckerlie, R. (2017). The flipped classroom for pre-clinical dental skills teaching - a reflective commentary. British Dental Journal, 222(9), 709-713.

Freitas, F. R. N., Souza, A. T. d. S., Carvalho, N. A. de, \& Pedrosa, J. I. dos S. (2020). Metodologias ativas de ensino nos cursos de medicina: uma revisão integrativa. Research, Society and Development, 9(7), e151973922. https://doi.org/10.33448/rsd-v9i7.3922

Fullan, M., \& Langworthy, M. (2014). A Rich Seam: How New Pedagogies Find Deep Learning. Pearson.

Galindo, J. J., \& Badilla, M. G. (2016). Teaching innovation through a flipped classroom methodoly: teachers and secondary education students' percepctions. Didasc@lia: Didáctica yEducación, 7(6), 153-172.

Galway, L. P., Corbett, K. K., Takaro, T. K., Tairyan, K., \& Frank, E. (2014). A novel integration of online and flipped classroom instructional models in public health higher education. BMC Medical Education, (14), 181. https://doi.org/10.1186/1472-6920-14-181

Gomes, A. T., Marques, J. S., Meneses, M. d. O., Leal, S. R. M. d. D., \& Brandão, S. A. d. S. M. (2020). Metodologias ativas como instrumento para um olhar sensível e acolhedor sobre a importância da vacinação em adolescentes. Research, Society and Development, 9(5), e79953131. https://doi.org/10.33448/rsdv9i5.3131

Gonçalves, L. M., Oliveira, A. M. d., \& Ferreira, A. G. (2020). O uso de metodologias ativas no ensino para estudantes de engenharia em uma universidade pública, em tempos de atividades remotas. Research, Society and Development, 9(10), e8819109131. https://doi.org/10.33448/rsd-v9i10.9131

Honório, H. L. G. (2017). Sala de aula invertida: uma abordagem colaborativa na aprendizagem de matemática [Master's dissertation, Universidade Federal de Juiz de Fora]. https://repositorio.ufjf.br/jspui/handle/ufjf/4783

Hora, K. E. R., Mesquita, G. G. M., \& Gomes, R. B. (2018). Analysis of reproach students in Environmental and Sanitary Engineering course at the Federal University of Goiás (EECA/UFG). Revista Eletrônica de Engenharia Civil, 4(1), 66-82.

Howard, S. W., Scharff, D. P., \& Loux, T. M. (2017). Flipping classrooms in a school of public health. Front Public Health, (5), 73.

Kasseboehmer, A. C., \& Ferreira, L. H. (2011). O método investigativo em aulas teóricas de química: estudo das condições da formação do espírito científico [Doctoral thesis, Universidade Federal de São Carlos]. https://repositorio.ufscar.br/handle/ufscar/6184

Lage, M. J., Platt, G. J., \& Treglia, M. (2000). Inverting the classroom: a gateway to creating an inclusive learning environment. Journal of Economic Education, 31(1), 30-43.

Magalhães, M. d. S. C., Sousa, Âdrea C. d., \& Azevedo, G. M. (2020). Contribuições da Preceptoria de Enfermagem no contexto da Atenção Primária à Saúde sob a perspectiva das metodologias ativas. Research, Society and Development, 9(7), e270973681. https://doi.org/10.33448/rsd-v9i7.3681

McLaughlin, J. E., Roth, M. T., Glatt, D. M., Gharkholonarehe, N., Davidson, C. A., Griffin, L. M., Esserman, D. A., \& Mumper, R. J. (2014). The flipped classroom: a course redesign to foster learning and engagement in a health professions school. Academic Medicine, 89(2), 236-243.

Milhorato, P. R., \& Guimarães, E. H. R. (2016). Challenges and possibilities of implementation of the inverted classroom methodology: case study in a private higher education institution. Revista de Gestão e Secretariado, 7(3), 253-276.

Mok, H. N. (2014). Teaching tip: the flipped classroom. Journal of Information Systems Education, 25(1), 7-11.

Njie-Carr, V. P. S., Ludeman, E., Lee, M. C., Dordunoo, D., Trocky, N. M., \& Jenkins, L. S. (2017). An integrative review of flipped classroom teaching models in nursing education. Journal of Professional Nursing, 33(2), 133-144.

Olitsky, N. H., \& Cosgrove, S. B. (2016). The better blend? Flipping the principles of microeconomics classroom. International Review of Economics Education, (21), 1-11.

Oliveira, C., Santos, F., Leitinho, J., \& Farias, L. (2018). Busca dos fatores associados à evasão: um estudo de caso no campus universitário da UFC em Crateús. Revista Internacional de Educação Superior, (5), e019006. 10.20396/riesup.v5i0.8652897.

Park, S. E., \& Howell, T. H. (2015). Implementation of a flipped classroom educational model in a predoctoral dental course. Journal of Dental Education, 79(5), 563-570.

Passos, F. G., Duarte, Sousa, G. M. C., Teles, R. S., \& Santos, V. M. L. (2007). Diagnóstico sobre a reprovação nas disciplinas básicas dos cursos de engenharia da UNIVASF. XXXV Congresso Brasileiro de Educação em Engenharia, Curitiba.

Pavanelo, E., \& Lima, R. (2017). Flipped classroom: the analysis of na experience in the discipline of Calculus I. Bolema, 31(58), 739-759.

Pérez-Sanagustín, M., Hilliger, I., Alario-Hoyos, C., Kloos, C. D., \& Rayyan, S. (2017). H-MOOC framework: reusing MOOCs for hybrid education. Journal of Computing in Higher Education, (29), 47-64. https://doi.org/10.1007/s12528-017-9133-5 
Research, Society and Development, v. 11, n. 2, e54411224721, 2022

(CC BY 4.0) | ISSN 2525-3409 | DOI: http://dx.doi.org/10.33448/rsd-v11i2.24721

Rodrigues, C. S., Spinasse, J. F., \& Vosgerau, D. S. R. (2015). Sala de aula invertida - uma revisão sistemática. XII Encontro Nacional de Educação, Curitiba.

Ryan, E., \& Reid, G. E. (2016). Chemical derivatization and ultrahigh resolution and accurate mass spectrometry strategies for "shotgun" lipidome analysis. Accounts of Chemical Research, 49(9), 1596-1604.

Santos, N. H., \& Sarinho, V. T. (2017). Dominó químico: jogo educativo para o ensino-aprendizagem das funções químicas inorgânicas. XVI SBGAMES, Curitiba.

Simpson, V., \& Richards, E. (2017). Flipping the classroom to teach population health: increasing the relevance. Nurse Education in Practice, 15 (3), $162-167$.

Sousa, F. A. (2016). Interatividade no fórum: possibilidade de aprendizagem colaborativa. EaD \& Tecnologias Digitais na Educação, 3(4), 75-85.

Souza, S. C., \& Dourado, L. (2015). Problem-Based Learning (PBL): a learning methodology for innovate educational teaching. Holos, (5), 182-200.

Suhr, I. R. F. (2016). Desafios no uso da sala de aula invertida no ensino superior. Revista Transmutare, 1(1), 4-21.

Touchton, M. (2015). Flipping the classroom and student performance in advanced statistics: evidence from a quasi-experiment. Journal of Political Science Education, 11 (1), 28-44.

Valente, J. A. (2015). A sala de aula invertida e a possibilidade do ensino personalizado: uma experiência com a graduação em midialogia. Retrieved January 3, 2022, from https://statics-submarino.b2w.io/sherlock/books/firstChapter/132759983.pdf

Valente, J. A., Almeida, M. E. B. d., \& Geraldini, A. F. S. (2017). Active methodologies: form conceptions to practices in different levels of teaching. Revista Diálogo Educacional, 17(52), 455-478.

Yamaguchi, K. K. L., \& Silva, J. d. (2019). Evaluating of low pass rates in General Chemistry at the Federal University of Amazon. Química Nova, 4(3), 346354.

Young, J. R. (2002). "Hybrid" teaching seeks to end the divide between traditional and online instruction. Chronicle of Higher Education, 48(22), 33-34.

Zanon, D. A. V., Guerreiro, M. A. S., \& Oliveira, R. C. (2008). Ludo chemical didactic game in the teaching of organic compositions nomenclature: project, production, application, and evaluation. Ciências \& Cognição, 13(1), 72-81. 